\title{
Factors that affect the physical science career interest of female students: Testing five common hypotheses
}

\author{
Zahra Hazari, ${ }^{1,2,3, *}$ Geoff Potvin, ${ }^{2,3}$ Robynne M. Lock, ${ }^{3}$ Florin Lung, ${ }^{4}$ Gerhard Sonnert, ${ }^{5}$ and Philip M. Sadler ${ }^{5}$ \\ ${ }^{1}$ Department of Teaching and Learning, Florida International University, Miami, Florida, USA \\ ${ }^{2}$ Department of Physics, Florida International University, Miami, Florida, USA \\ ${ }^{3}$ Department of Engineering and Science Education, Clemson University, Clemson, South Carolina, USA \\ ${ }^{4}$ Department of Physics and Astronomy, Mississippi State University, Mississippi State, Mississippi, USA \\ ${ }^{5}$ Science Education Department, Harvard-Smithsonian Center for Astrophysics, Cambridge, Massachusetts, USA
}

(Received 8 August 2012; revised manuscript received 28 June 2013; published 22 October 2013)

There are many hypotheses regarding factors that may encourage female students to pursue careers in the physical sciences. Using multivariate matching methods on national data drawn from the Persistence Research in Science and Engineering (PRiSE) project $(n=7505)$, we test the following five commonly held beliefs regarding what factors might impact females' physical science career interest: (i) having a single-sex physics class, (ii) having a female physics teacher, (iii) having female scientist guest speakers in physics class, (iv) discussing the work of female scientists in physics class, and (v) discussing the underrepresentation of women in physics class. The effect of these experiences on physical science career interest is compared for female students who are matched on several factors, including prior science interests, prior mathematics interests, grades in science, grades in mathematics, and years of enrollment in high school physics. No significant effects are found for single-sex classes, female teachers, female scientist guest speakers, and discussing the work of female scientists. However, discussions about women's underrepresentation have a significant positive effect.

DOI: 10.1103/PhysRevSTPER.9.020115

PACS numbers: 01.40.Fk, 01.40.ek, 01.40.G-

\section{INTRODUCTION}

Driven by equity concerns and worries about insufficient capacity building in science, female representation in the physical sciences continues to be a topic of high priority among scientists, educators, policy makers, and education researchers. Unlike the biological sciences, which reached gender parity for U.S. bachelor's degrees by 1989, the physical sciences continue to suffer female underrepresentation with some of the largest gaps occurring in physics [1]. There has been wide speculation with regards to why such disparities continue to exist and what could be done to narrow the gap. The most common reasons cited include unsupportive classroom environments and widely held characterizations of the physical sciences as "masculine" enterprises [2,3]. In response to these issues, it has been hypothesized that single-sex physics classes, female role models in physics, and a better understanding of issues relevant for women in physics may provide solutions [4,5].

\section{BACKGROUND}

Unsupportive classroom environments, particularly in physics, appear in the research literature on gender in

\footnotetext{
*Corresponding author. zahra@clemson.edu

Published by the American Physical Society under the terms of the Creative Commons Attribution 3.0 License. Further distribution of this work must maintain attribution to the author(s) and the published article's title, journal citation, and DOI.
}

multiple ways, including teachers who focus on male students or allow them to dominate whole-group classroom interactions [6,7], male students who dominate the interactions during small group activities [8,9], instructional content containing more contextual relevance and topics of interest to males [7,10], and the lack of meaningful engagement in thinking about science concepts, particularly for female students [11-14]. Thus, it is conceivable that single-sex physics may provide a solution because separating the female students would allow the teacher to focus more attention on them as well as adapt the instruction to their needs [4].

Research studies on the effect of single-sex classes in countries similar to the U.S. have produced a spectrum of results. Several studies have found that female students who have had single-sex physics experiences have a stronger physics-related self-concept $[10,15,16]$, show greater preference for or persistence in studying the subject $[17,18]$, and perform at higher levels [16,17]. However, education researchers who have focused on single-sex issues have often warned that single-sex classrooms may not be a solution in and of themselves [2,10,19]. For example, Haussler and Hoffmann write in the context of German single-sex physics classes that "monoeducation is effective only when it goes hand-in-hand with a change in the curriculum" [10]. This note of caution resonates strongly with national research from New Zealand that has found that single-sex experiences have no effect on physics performance outcomes after accounting for prior 
academic performance (there was a greater percentage of high-achieving females in single-sex classes) [20].

The complexity of the issue is further revealed when student characteristics are examined in more detail. For example, a study at a secondary school in the United Kingdom found benefits of single-sex instruction for 13 year old female students in courses of a higher academic track, in terms of both physics achievement and preference, but not for females on a lower track [21]. A Canadian study conducted at a coeducational public high school and employing controls to account for confounding variables (e.g., prior mathematics achievement) found that singlesex math and science instruction in 9th and 10th grades had positive effects on performance and persistence (course enrollment) but not on perceptions or attitudes related to mathematics, mathematics anxiety, or mathematics competence [22]. This is contrary to other work that has found that single-sex experiences have the most notable impact on girls' perceptions and attitudes [2]. However, reviews of single-sex classrooms, particularly in the U.S., continue to challenge these environments as solutions for girls, in part because they do not necessarily eliminate gender stereotyping and because positive results are highly dependent on gender-inclusive teaching practices $[2,23,24]$. Furthermore, another study in the United Kingdom found that many teachers do not adjust their coeducational teaching practices when teaching single-sex classes [19]. Thus, more work on single-sex education is needed; work that goes beyond single classroom or school studies and controls for confounding variables.

Another issue arising from the literature is the stereotypic views of physical scientists and the culture of physical science fields as overtly masculine [25]. These types of stereotypes are not new, and policy recommendations for decades have pointed to the importance of female role models as a means to countering and addressing these narrow perceptions [2]. It is hypothesized that being exposed to female role models in the physical sciences will counter stereotypes while helping female students realize their potential to engage in physical science fields and fit into physical science communities (since other women have successfully done so). Tindall and Hamil [5] write, "Teachers need to actively provide female role models, in person and in print, including female scientists and contributions of women in science. When girls are provided with a rich background of female role models they are able to picture themselves in science careers." In particular, such role models can be presented in the form of examples of female scientists as well as interactions with actual female scientists and science teachers. Steele [26] identified the use of role models as part of his "wise schooling" policies and practices in order to help students overcome experiencing stereotype threats.

Similar to the research on single-sex experiences, work on role modeling has also produced contrasting results. For example, one study found that the number of female faculty in high school science departments had no impact on the choice of a STEM (science, technology, engineering, mathematics) career for either female or male students [27]. In contrast, another study of 197 institutions of higher education in the United States found that the percentages of women among undergraduate science or engineering majors and degree recipients positively correlated with the percentages of women among the faculty in these fields [28]. Another large-scale study of students enrolled at fouryear public universities in Ohio found that, for female students, having a female instructor for their initial course in a subject was a positive predictor of taking subsequent courses in the subject for mathematics or statistics and geology, but was not significant in the case of chemistry, engineering, and computer science, and even a negative predictor for physics [29]. In addition, no significant effects of initially having a female instructor were found on college major choice for any of the sciences. Other work [30] found no evidence of an effect of high school teacher gender on students' later college science persistence, nor on their college science performance in biology, chemistry, and physics.

Some studies have found significant positive effects of different types of female role modeling on female students' performance and attitudes. For example, Marx and Roman found that exposure to a female role model in mathematics (a competent female administering the test) improved mathematics performance for female college students who were motivated and identified with mathematics [31]. In another quasiexperiment, an intervention using female role models was found to improve the attitudes of ninth grade students, both male and female, towards science- and math-related careers [32]. However, the study was unable to disaggregate the effect of seeing the three female role models conducting the intervention (science teacher, university engineering student, university science student) and the intervention itself, which involved discussing stereotypes and science or engineering career options. It is important to note that many university outreach programs include female scientists and science students visiting K-12 science classes to discuss their work and serve as role models for girls and young women, particularly in fields where women are underrepresented, such as physics and engineering. Despite these widespread efforts, little is known about the direct effect that this type of role modeling has on female students' choice of a science-related field.

Moving beyond role modeling to address stereotypic views regarding the physical sciences, research also indicates that interventions that buffer or counter students' stereotypic perceptions, by either refuting stereotypes [26,33] or affirming their own values [34], can reduce gender gaps in achievement. Thus, it can be hypothesized that reflection on stereotypes and underrepresentation 
issues for women in the physical sciences, an act which may lead to greater self-realization for female students, may also have an effect on their choice of a physical science career. For example, discussions regarding issues that women face in pursuing the physical sciences may help female students realize that their feelings of inadequacy or discomfort are stemming from external norms and pressures rather than their own capabilities and interests. Steele [26] identified several such practices as part of his "wise schooling" recommendations that may help otherwise marginalized students to overcome these barriers, including "affirming domain belongingness" and "valuing multiple perspectives."

To examine the efficacy of the solutions put forth in the literature, this study tests the effects of five high school physics classroom experiences on female students' interest in pursuing a career in the physical sciences: (i) having a single-sex physics class, (ii) having female scientist guest speakers, (iii) having a female physics teacher, (iv) discussing the work of female scientists, and (v) discussing the underrepresentation of women. Using national survey data, the effect of these five conditions was tested using multivariate matching methods [35] to compare matched groups of females who experienced and did not experience each of the five conditions.

\section{METHODS}

This study draws on data from the Persistence Research in Science and Engineering (PRiSE) project, which surveyed a national sample of college English students (7505 students at 40 institutions) in order to capture data from a wide range of students, including both those who were interested in the physical sciences and those who were not. The PRiSE study included a stratified random sample of 34 colleges and universities (by size of school and type-2 year or 4 year) and 6 additional, oversampled schools to ensure adequate representation of students from underrepresented populations in STEM who were interested in STEM careers (1 historically Black college, 1 Hispanic-serving college, and 4 women's colleges). Since the focus of this study was the effect of certain high school physics experiences on female students' interest in a physical science career, the sample used in the analysis included data from 1580 female respondents who had taken high school physics.

The PRiSE survey had 50 items which were validated and tested for reliability [36]. Content and face validity were established through focus groups with college students and STEM education experts (both researchers and practitioners). Further, content validity was established through open-ended online surveys with 412 science teachers and professors to incorporate the breadth of views and hypotheses posed by the community. The survey was pilot tested with 49 students so that item scales and wording could be adjusted to reflect the variation in student experiences and for understandability. To ensure stability of the instrument, a test-retest reliability study with 96 students over a 2-3 week interval resulted in a mean reliability coefficient of 0.7 corresponding to a $0.04 \%$ likelihood of a reversal of an effect [37].

The dependent variable used in this study was an anchored 6-point scale asking students to rate the likelihood of their choosing a career in the physical sciences from "0-Not at all likely" to "5-Extremely likely." The concurrent criterion-related validity of this measure was assessed by examining how well it predicted students' intended choice of career reported in another part of the survey with dichotomous variables (i.e., students could select physicist, chemist, etc.). A logistic regression revealed that a 1-point increase on the scale corresponded to a 1.82:1 increase in the odds of intending a career as a physicist or chemist $(p<0.001)$. Thus, a 1-point increase in the scale almost doubled the odds of intending to be a physicist or chemist. This result strengthened our confidence in the validity of our chosen dependent variable. The focal items for addressing the posed hypotheses were the following:

- What was the distribution of male and female students in your last high school physics course? $1=$ All females, $2=$ More females than males, $3=$ About equal, $4=$ More males than females, $5=$ All males. The scale was transformed into a binary variable with $1=$ All females and $0=$ Coeducational. All-male courses were not considered in this analysis.

- Please indicate whether the following occurred in your last high school physics class: Female scientist guest speakers. This was a binary variable with $1=$ Yes and $0=$ No.

- Please indicate whether the following were discussed in your last high school physics class: Work of female scientists. This was a binary variable with $1=$ Yes and $0=$ No.

- Please indicate whether the following were discussed in your last high school physics class: Underrepresentation of women in science. This was a binary variable with $1=$ Yes and $0=$ No.

- Gender of last high school physics teacher. This was a binary variable with $1=$ Female and $0=$ Male.

The background control variables (covariates) were the following:

- In middle school, how interested were you in science? From $1=$ Not interested at all, to $6=$ Extremely interested.

- In middle school, how interested were you in mathematics? From $1=$ Not interested at all, to $6=$ Extremely interested.

- Grade in last high school science and last high school mathematics class (GPA scale).

- Number of years of high school physics. Students who did not take a high school physics class were not included since the hypotheses being tested were about experiences in high school physics. 
These covariates were selected because they were all significant predictors of physical science career interest.

This study used a causal comparative or ex post facto approach [38] on observational data to simulate the structure of an experimental approach. Using multivariate matching techniques [35,39], similar to propensity score matching, we were able to compare groups of females who were equivalent on the confounding covariates. This method proceeds in a few steps. First, the individuals in the data are identified as being part of the "treatment" or "control" groups by virtue of having reported (or not) each of the five hypothesized experiences identified above. Then, an algorithmic process uses the covariates identified above to numerically identify the optimal balance, or measure of "distance," on the covariates [39]. Third, each individual in the treatment group is matched with an individual in the control group who is closest on the covariates (according to the results of the previous step), and a set of diagnostic statistics provides evidence for the goodness of the matching procedure. Lastly, the dependent variable is tested for differences between the now-matched treatment and control groups. In other words, we matched students in the treatment and control groups on the covariates so that the females in both groups had almost equal prior science and math interest, equal science and math grades, and the same number of years taking high school physics, and then examined the effect of the five experiences on their physical science career interests. The matching methods allow the use of observational data to estimate causal relationships similar to those manipulated through direct experimental designs. However, these approaches enable greater inferential flexibility in collecting information on factors that cannot be easily manipulated in an experimental setting (for practical and/or ethical reasons) and for sampling from larger, more representative populations, thereby increasing statistical power and generalizability. Table I summarizes the means of the covariates being matched between treatment and control groups, both before and after matching. After matching, there were no significant differences between treatment and control

TABLE I. Covariate means before and after matching for each of the five conditions. (MS, middle school; HS, high school.)

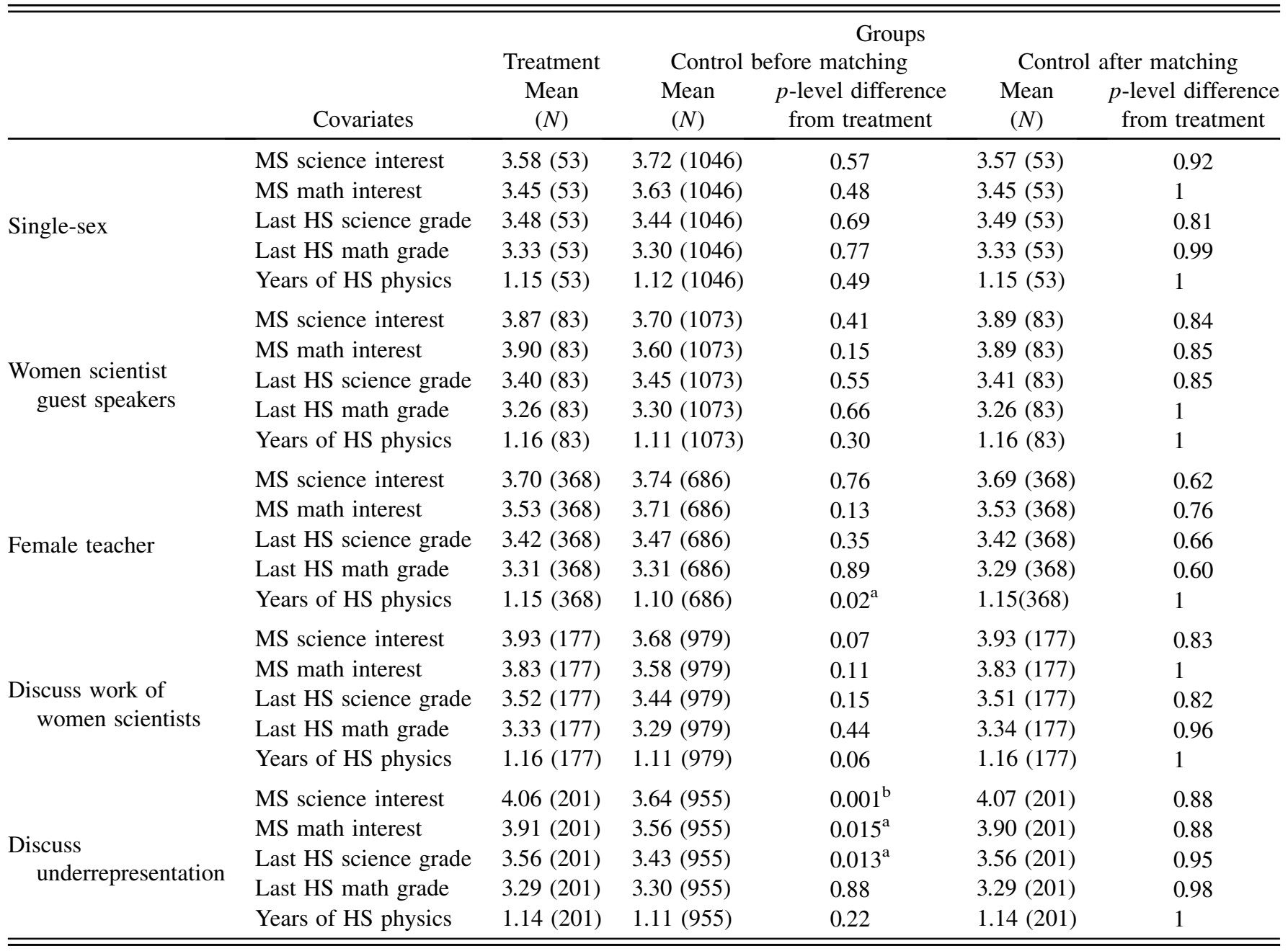

${ }_{\mathrm{a}}^{\mathrm{a}} p<0.05$
${ }_{p}<0.01$ 
TABLE II. T-test difference between treatment and control groups after matching for each of the five conditions. (SE, standard error.)

\begin{tabular}{lcccc}
\hline \hline & \multicolumn{4}{c}{$\begin{array}{c}\text { Likelihood of choosing a career } \\
\text { in the physical sciences }\end{array}$} \\
& Estimate & SE & Effect size & $p$ \\
\hline Treatment & & & & \\
$\quad$ Single-sex class & -0.07 & 0.27 & -0.05 & 0.80 \\
Women scientist & 0.10 & 0.20 & 0.06 & 0.61 \\
$\quad$ guest speakers & & & & \\
Female teacher & 0.13 & 0.12 & 0.08 & 0.27 \\
Work of women & 0.30 & 0.16 & 0.18 & 0.05 \\
$\quad$ scientists & & & & \\
Discussion of & 0.44 & 0.15 & 0.27 & $0.004^{\mathrm{b}}$ \\
$\quad$ underrepresentation & & & & \\
\hline \hline
\end{tabular}

$\overline{\mathrm{b}_{p}<0.01 \text {. }}$

groups on any covariate for any of the five conditions being tested ( $p=0.60$ to $p=1.0$ ) and differences were narrowed in all but one (nonsignificant) case by employing the matching methods. One surprising finding is that female students in single-sex physics classes were not significantly different from the rest of the female population taking high school physics on any of the covariates.

\section{RESULTS}

Comparing the matched groups allowed us to ascertain the specific effect of each of the five classroom conditions on students' interest in a physical science career since the treatment (having the particular classroom experience) and control (not having the classroom experience) groups were equalized on background characteristics that also influence physical science career interest. The results are summarized in Table II and Fig. 1. Four of the five conditions yielded no significant effects at the $\alpha=0.05$ level. These nonsignificant experiences included having a single-sex physics class $(B=-0.07, \quad t=-0.26, \quad p=0.80$, Cohen's $d=-0.05)$, having female scientist guest speakers visit class $(B=0.10, t=0.51, p=0.61, d=0.06)$, having a female physics teacher $(B=0.13, t=1.10$, $p=0.27, d=0.08)$, and discussing the work of female scientists $(B=0.30, t=1.93, p=0.05, d=0.18)$. Although discussing the work of female scientists was almost significant, based on our alpha level we cannot reject the null hypothesis. A strongly significant effect was obtained for discussion of the underrepresentation of women $(B=0.44, t=2.92, p<0.01, d=0.27)$, with female students who were exposed to such discussions being significantly more likely to choose a physical science career than those who were not, by nearly half of a point on the 6-point scale. The effect, however, is still relatively small (effect sizes for Cohen's $d$ in the range of $0.2-0.3$ are considered small) [40], which is expected since it is just one physics class experience from among a myriad of in-class and outof-class experiences that also impact career choice.

Since these experiences do not necessarily happen in isolation (e.g., discussion of underrepresentation may begin with discussion of the work of female scientists), it is also necessary to consider them in conjunction. The percentage overlap between the five conditions is reported in Table III. There was significant overlap between the five conditions. Most notably, female teachers significantly

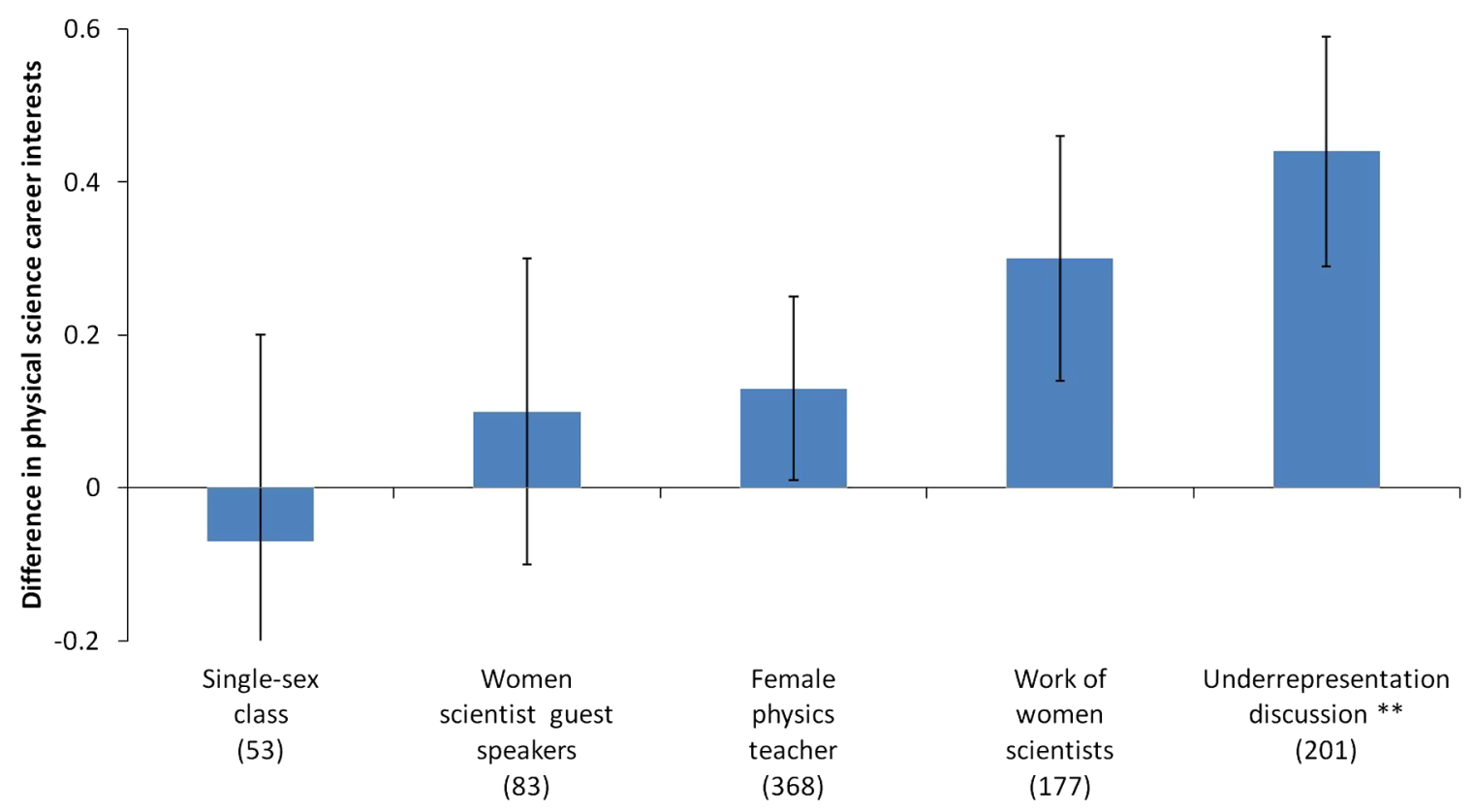

FIG. 1 (color online). Difference in treatment and control group means for physical science career interest (6-point scale) for five high school physics classroom conditions ( $n$ for each group in parentheses). Error bars represent \pm 1 standard error. $* *$ denotes $p<0.01$. 
TABLE III. Percentage overlap in experiencing the conditions with pairwise chi-squared tests to denote significance (note that this is only for female students). For example, among female students who reported experiencing women scientist guest speakers, $6.5 \%$ had single-sex physics classes.

\begin{tabular}{|c|c|c|c|c|c|}
\hline \multirow[b]{2}{*}{ Experience } & \multicolumn{5}{|c|}{ Overlap } \\
\hline & $\begin{array}{l}\text { Single-sex } \\
\text { class }\end{array}$ & $\begin{array}{l}\text { Women scientist } \\
\text { guest speakers }\end{array}$ & $\begin{array}{l}\text { Female } \\
\text { teacher }\end{array}$ & $\begin{array}{l}\text { Women scientist } \\
\text { examples }\end{array}$ & $\begin{array}{c}\text { Discussion of } \\
\text { underrepresentation }\end{array}$ \\
\hline Single-sex class & $\cdots$ & 11.4 & $60.3^{\mathrm{c}}$ & 24.3 & $32.9^{\mathrm{b}}$ \\
\hline Coeducational class & $\cdots$ & 8.2 & 34.6 & 16.7 & 17.0 \\
\hline Women scientist guest speakers & 6.5 & $\cdots$ & $49.2^{\mathrm{b}}$ & $53.9^{\mathrm{c}}$ & $43.8^{\mathrm{c}}$ \\
\hline No women scientist guest speakers & 4.6 & $\cdots$ & 34.8 & 12.9 & 14.9 \\
\hline Female teacher & $7.9^{\mathrm{c}}$ & $11.5^{\mathrm{b}}$ & $\cdots$ & $22.3^{\mathrm{c}}$ & $20.9^{\mathrm{b}}$ \\
\hline Male teacher & 2.9 & 6.7 & $\cdots$ & 13.1 & 15.3 \\
\hline Work of women scientists & 6.7 & $26.8^{\mathrm{c}}$ & $48.9^{\mathrm{c}}$ & $\cdots$ & $48.6^{\mathrm{c}}$ \\
\hline No work of women scientists & 4.3 & 4.5 & 33.4 & $\cdots$ & 11.2 \\
\hline Discussion of underrepresentation & $8.7^{\mathrm{b}}$ & $20.5^{\mathrm{c}}$ & $43.4^{\mathrm{b}}$ & $45.8^{\mathrm{c}}$ & $\cdots$ \\
\hline No discussion of underrepresentation & 3.8 & 5.5 & 34.4 & 10.1 & $\ldots$ \\
\hline
\end{tabular}

${ }^{\mathrm{b}} p<0.01$.

${ }^{c} p<0.001$.

overlapped with all four other conditions, as did discussion of underrepresentation. Thus, female teachers are more likely to teach all-female classes, bring in women scientist guest speakers, discuss the work of women scientists, and discuss underrepresentation. Similarly, discussions of underrepresentation are more likely coupled with allfemale classes, women scientists guest speakers, having a female teacher, and discussing the work of women scientists. We included all five conditions simultaneously in a multiple regression model (also containing the variables that were previously matched on) so as to estimate the effects of the individual conditions while controlling for the effects of all others. Additionally, we tested all the interaction effects between all possible pairs of the conditions on the outcome of physical science career interest in this regression model. In other words, we simultaneously tested all main effects of the conditions and their interactions. All interaction effects were nonsignificant, but the main effect for the discussion of underrepresentation remained significant $(p=0.02)$ in the final model which included only significant variables. We conclude, therefore, that there was no detectable combined effect for multiple conditions acting simultaneously.

\section{DISCUSSION}

Although many of the hypothesized solutions showed no effect on physical science career interest, the results still leave room for optimism because they suggest that there are avenues for classroom practice to positively impact females' interest in pursuing the physical sciences. Furthermore, these avenues are accessible to all teachers because they do not require female students to be separated from males or the presence of a female teacher. Despite the fact that some prior research on the effect of single-sex classrooms has shown contrasting outcomes, many studies have reported null results similar to ours [2]. It is likely that null results of single-sex physics experiences are due to the fact that such experiences are not coupled with genderinclusive curricular reform. Haussler and Hoffmann [10] write, "separating girls and boys in physics classes is probably ineffective when not supported by a girl-friendly curriculum and a gender-fair teacher." Furthermore, Younger and Warrington [19], in their study of the implementation of single-sex classes in a coeducational secondary school, found that "... whilst some teachers did explicitly adjust their teaching style and strategies to meet the perceived differing needs of boys and girls, and plan lessons accordingly, the majority did not make any explicit adjustments, regardless of whether the class is composed of boys, girls or both."

Prior research has also found that the gender of science teachers has little effect on students' science career choice and that it is the relationship students have with those teachers that makes a difference. Gilmartin et al. [27] found that high school students positively responded to science teachers who were "energetic, caring, passionate, and patient, with high expectations for student success" without "explicit preference for male or female teachers, attributing positive and negative characteristics to each in ostensibly "nongendered" ways." This same reasoning, emphasizing the importance of building meaningful relationships, may explain why female scientist guest speakers had no effect; students may not have had the opportunity to build meaningful relationships with female scientists who visited on isolated occasions.

Our null results with respect to female role modeling are particularly important because of the common belief that 
such role modeling is necessary for attracting females. As mentioned above, it is likely that the relationships developed with significant others in the context of the discipline are critically important, regardless of the gender of those significant others. Results from an international study of women in physics conducted by the American Institute of Physics [41] found that a large number of women physicists reported that a person influenced their choice of career, with the influence of a teacher, not necessarily female, being the most frequently cited (50\%). Thus, male teachers can influence the choices of female students just as much as female teachers can through building positive relationships and implementing practices found to be positive, such as the discussion of underrepresentation. This is particularly important since we found that male teachers are less likely to implement practices that were hypothesized to encourage female students. This may also reveal a level of disempowerment on the part of male teachers to impact change for female students - they may feel the gender mismatch to be an impediment and feel unable to identify possible solutions to help female students in particular.

As research on gender issues in physics moves forward, it is necessary to ask more nuanced questions about the nature of positive relationships, i.e., how or why these relationships influence girls' interests, rather than defaulting to general and unsupported statements about female role models. In their study of a group of women scientists, Gilbert and Calvert [42] found that "... participants said that good female 'role models' were important to young women in science education. However, when asked, none of the women could produce any convincing stories illustrating the significance of role models in their lives (either in the form of actual people or in stories in books)." Future research should move past traditional lore by demanding evidence for proposed solutions, providing a sophisticated understanding of the ways and conditions in which such solutions apply, and developing explanatory frameworks for the effects identified. This is particularly important in the U.S. because female representation has stagnated in physics over the past few years [1].

Prior research has also pointed to the importance of students' self-realization for educational outcomes, which may be fostered by interventions that directly counteract students' stereotypic beliefs [26,33] or affirm their personal values more broadly, resulting in increased engagement, grit, or confidence [34]. Perhaps engaging in discussions around underrepresentation affords more opportunities for female students' self-realization about physics because the act of discussing may incorporate their perspectives, rather than being inherently teacher centered, and help to affirm their domain belongingness, in Steele's language [26]. By contrast, a presentation from a female scientist or simply having a female teacher is less student centered and may, therefore, be more difficult to translate into students' selfrealization. In other words, explicit personal discussions regarding issues that women face in pursuing the physical sciences may help female students realize that feelings of inadequacy or discomfort they might have stem from external norms and pressures rather than from their capabilities, interests, or values. In keeping with our recommendations above for more nuanced research, it is important to follow up this work by more deeply probing how and why such discussions might help female students. Thus, our future work will tackle this issue by developing, through evidence, explanatory frameworks for understanding why discussions of underrepresentation might help and how they can best be implemented in the classroom.

\section{ACKNOWLEDGMENTS}

This material is based upon work supported by the National Science Foundation under Grants No. GSE0624444 and No. DRL-0952460.
[1] National Science Foundation Report No. 10-01, 2010 [http://www.nsf.gov/statistics/seind10/].

[2] K. Scantlebury and D. Baker, in Handbook of Research on Science Education, edited by S. Abell and N. Lederman (Lawrence Erlbaum, Mahwah, NJ, 2007), pp. 257-286.

[3] J. S. Brotman and F. M. Moore Girls and science: A review of four themes in the science education literature, J. Res. Sci. Teach. 45, 971 (2008).

[4] L. Parker and L. Rennie, Teachers' implementation of gender-inclusive instructional strategies in single-sex and mixed-sex science classrooms, Int. J. Sci. Educ. 24, 881 (2002).

[5] T. Tindall and B. Hamil, Gender disparity in science education: The causes, consequences, and solutions, Education 125, 2 (2004) [http://eric.ed.gov/?id=EJ698726].
[6] S. Chambers and T. Andre, Gender, prior knowledge, interest, and experience in electricity and conceptual change text manipulations in learning about direct current, J. Res. Sci. Teach. 34, 107 (1997).

[7] H. Stadler, R. Duit, and G. Benke, Do boys and girls understand physics differently?, Phys. Educ. 35, 417 (2000).

[8] P. Heller, and M. Hollabaugh, Teaching problem solving through cooperative grouping, Part 2: Designing problems and structuring groups, Am. J. Phys. 60, 637 (1992).

[9] P. Laws, P. Rosborough, and F. Poodry, Women's responses to an activity-based introductory physics program, Am. J. Phys. 67, S32 (1999).

[10] P. Haussler, and L. Hoffmann, An intervention study to enhance girls' interest, self-concept, and achievement in physics classes, J. Res. Sci. Teach. 39, 870 (2002). 
[11] A. M. Cavallo, W.H. Potter, and M. Rozman, Gender differences in learning constructs, shifts in learning constructs, and their relationship to course achievement in a structured inquiry, yearlong college physics course for life science majors, School Sci. Math. 104, 288 (2004).

[12] Z. Hazari, G. Sonnert, P. M. Sadler, and M.-C. Shanahan, Connecting high school physics experiences, outcome expectations, physics identity, and physics career choice: A gender study, J. Res. Sci. Teach. 47, 978 (2010).

[13] J. A. Marshall and J. T. Dorward, Inquiry experiences as a lecture supplement for preservice elementary teachers and general education students, Am. J. Phys. 68, S27 (2000).

[14] K. Williams, Understanding, communication anxiety and gender in physics, J. Coll. Sci. Teach. 30, 232 (2000).

[15] U. Kessels and B. Hannover, When being a girl matters less: Accessibility of gender-related self-knowledge in single-sex and coeducational classes and its impact on students' physics-related self-concept of ability, Br. J. Educ. Psychol. 78, 273 (2008).

[16] J. Streitmatter, Single-sex classes: Female physics students state their case, School Sci. Math. 98, 369 (1998).

[17] E. Gillibrand, P. Robinson, R. Brawn, and A. Osborn, Girls' participation in physics in single sex classes in mixed schools in relation to confidence and achievement, Int. J. Sci. Educ. 21, 349 (1999).

[18] A. Stables, Differences between pupils from mixed and single-sex schools in their enjoyment of school subjects and in their attitudes to science and to school, Educ. Rev. 42, 221 (1990).

[19] M. Younger, and M. Warrington, Single-sex teaching in a co-educational comprehensive school in England: An evaluation based upon students' performance and classroom interactions, Br. Educ. Res. J. 28, 353 (2002).

[20] R. Harker, Achievement, gender and the single-sex/coed debate, Br. J. Sociol. Educ. 21, 203 (2000) [http:// www.tandfonline.com/doi/abs/10.1080/ 713655349\#.Uk7acODU_MV].

[21] W. Robinson, and E. Gillibrand, Single-sex teaching and achievement in science, Int. J. Sci. Educ. 26, 659 (2004).

[22] J. Shapka and D. Keating, Effects of a girls-only curriculum during adolescence: Performance, persistence, and engagement in mathematics and science, Am. Educ. Res. J. 40, 929 (2003).

[23] V.E. Lee, H. M. Marks and T. Byrd, Sexism in single-sex and coeducational independent secondary school classrooms, Sociol. Educ. 67, 92 (1994).

[24] F. Mael, Single-sex and coeducational schooling: Relationships to socioemotional and academic development, Rev. Educ. Res. 68, 101 (1998).

[25] U. Kessels, M. Rau, and B. Hannover, What goes well with physics? Measuring and altering the image of science, Br. J. Educ. Psychol. 76, 761 (2006).
[26] C. Steele, A threat in the air: How stereotypes shape intellectual identity and performance, Am. Psychol. 52, 613 (1997).

[27] S. K. Gilmartin, N. Denson, E. Li, A. Bryant, P. Aschbacher, Gender ratios in high school science departments: The effect of percent female faculty on multiple dimensions of students' science identities, J. Res. Sci. Teach. 44, 980 (2007).

[28] G. Sonnert, M.F. Fox, and K. Adkins, Undergraduate women in science and engineering: Effects of faculty, fields, and institutions over time, Soc. Sci. Q. 88, 1333 (2007).

[29] E. P. Bettinger and B. T. Long, Do faculty serve as role models? The impact of instructor gender on female students, Am. Econ. Rev. 95, 152 (2005).

[30] G. Potvin, Z. Hazari, R. H. Tai, and P. M. Sadler, Unraveling bias from student evaluations of their high school science teachers, Sci. Educ. 93, 827 (2009).

[31] D. M. Marx and J.S. Roman, Female role models: Protecting women's math test performance, Pers. Soc. Psychol. Bull. 28, 1183 (2002).

[32] M. A. Evans, M. Whigham, and M. C. Wang, The effect of a role model project upon the attitudes of ninth-grade science students, J. Res. Sci. Teach. 32, 195 (1995).

[33] I. Dar-Nimrod, and S. J. Heine, Exposure to scientific theories affects women's math performance, Science 314, 435 (2006).

[34] A. Miyake, L.E. Kost-Smith, N. D. Finkelstein, S. J. Pollock, G. L. Cohen, and T. A. Ito, Reducing the gender achievement gap in college science: A classroom study of values affirmation, Science 330, 1234 (2010).

[35] J.S. Sekhon, Multivariate and propensity score matching software with automated balance optimization: The matching package for R, J. Stat. Software $\mathbf{4 2}$ (2011) [http://www.jstatsoft.org/v42/i07].

[36] P. M. Sadler, G. Sonnert, Z. Hazari, and R. H. Tai, Stability and volatility of STEM career choice in high school: A gender study, Sci. Educ. 96, 411 (2012).

[37] R.M. Thorndike, Measurement and Evaluation in Psychology and Education (Merrill, Upper Saddle River, NJ, 1997), 6th ed., pp. 116-117.

[38] L. R. Gay, G. E. Mills, and P.W. Airasian, Educational Research: Competencies for Analysis \& Applications (Prentice-Hall, Upper Saddle River, NJ, 2006), 8th ed.

[39] D. B. Rubin, Bias reduction using mahalanobis-metric matching, Biometrics 36, 293 (1980)

[40] J. Cohen, Statistical Power Analysis for the Behavioral Sciences (Lawrence Erlbaum, Hillsdale, NJ, 1988), 2nd ed.

[41] R. Ivie and S. Guo, AIP Publication No. R-441, 2006 [http://www.aip.org/statistics/trends/reports/iupap05.pdf].

[42] J. Gilbert and S. Calvert, Challenging accepted wisdom: Looking at the gender and science education question through a different lens, Int. J. Sci. Educ. 25, 861 (2003). 